\title{
Nitrate poisoning in cattle. 3 . The relationship between nitrate intake with hay or fresh roughage and the speed of intake on the formation of methemoglobin
}

\author{
J. H. Geurink ${ }^{1}$, A. Malestein ${ }^{2}$, A. Kemp ${ }^{1}$ and A. Th. van 't Klooster ${ }^{2}$ \\ 1 Centre for Agrobiological Research, Wageningen, the Netherlands \\ 2 Zootechnical Institute, State University, Utrecht, the Netherlands
}

Accepted: 17 April 1979

Key words: cattle, nitrate poisoning, methemoglobin formation, intake, speed of intake, roughages

\section{Summary}

Some 40 feeding experiments were carried out with dry or lactating Friesian cows. The rations consisted of hay, grass pellets, turnips or freshly mown grass. Per meal the nitrate intake, water consumption, speed of intake of the nitrate were continuously and automatically recorded. During the experiments all the experimental animals were provided with a catheter in the jugular vein to facilitate frequently taking of blood samples (every 15 minutes) to determine $\mathrm{Hb}$ and $\mathrm{MHb}$ (as a percentage of total $\mathrm{Hb}$ ) in the blood. In this paper only results are mentioned of animals after being supplied with at least four meals of nitrate-rich roughage (nitrateadapted animals).

All the experiments show a positive relation between the amount of nitrate consumed and the $\mathrm{MHb}$ percentage in the blood. However, wide differences within and between the various roughages were found in $\mathrm{MHb}$ formation at equal nitrate intakes. It was demonstrated that these differences could partly be explained from the speed at which the nitrate rich feed was consumed. At equal nitrate intake less $\mathrm{Hb}$ is converted to $\mathrm{MHb}$ in the blood as the intake of nitrate is slower. Besides, the kind of roughage with which the nitrate was taken in was found to be of importance. At equal nitrate intake and equal speed of nitrate intake, with hay considerably more $\mathrm{Hb}$ was converted into $\mathrm{MHb}$ than with freshly mown grass. This was related to the speed at which the nitrate consumed with the roughage is released in the rumen as a substrate for the rumen flora.

An experiment in vitro showed that with preserved roughage (hay) the nitrate present in the cells after submerging in distilled water was diffused into the water for upwards $80 \%$ after 20 minutes. With fresh products like turnips and grass after chopping to about $1 \mathrm{~cm}$, a maximum of $30 \%$ of the nitrate present in the roughage was diffused into the water after 20 minutes of submergence. 


\section{Introduction}

The nitrate taken in with the feed by ruminants is partly reduced by micro-organisms in the rumen to nitrite and this, though at a slower rate, to ammonia. With a high nitrate intake nitrite will accumulate in the rumen liquid. This nitrite is rapidly absorbed from the rumen into the blood, where it converts $\mathrm{HbO}_{2}$ (oxyhemoglobin) into MHb (methemoglobin) (Gamgee, 1868; Vertregt, 1977) and leads to low blood pressure (Asbury \& Rhode, 1964; Malestein et al., 1979). The formation of $\mathrm{MHb}$ as well as the lower blood pressure (caused by the absorbed nitrite) affect the oxygen capacity of the blood adversely.

There is great controversy in the literature with respect to the acceptable dose of nitrate to be supplied to bovines without adverse effects. The wide differences in these doses can be partly explained. In an earlier paper Kemp et al. (1977) demonstrated that the acceptable dose of nitrate consumed during the first day is appreciably higher than when a nitrate-rich ration has already been fed for some days. Nevertheless, allowing for this phenomenon, the variation in the relation between nitrate intake and $\mathrm{MHb}$ formation remained wide enough to suggest that other factors could be involved as well.

Crawford (1960) and Dollahite \& Holt (1970) already suggested that the speed of intake of nitrate-rich forage would be certainly important in the accumulation of nitrite in the rumen fluid and in the conversion of $\mathrm{HbO}_{2}$ into $\mathrm{MHb}$ in the blood. Since the intake of feed and water was recorded continuously and automatically in all our experiments during the last five years (Kemp et al., 1976, 1978a, 1978b), data on the speed of intake are available. In this paper we will demonstrate that besides the dose of nitrate taken in, the speed of intake of the nitrate-rich roughage and the kind of nitrate-rich roughage are important in the formation of $\mathrm{MHb}$ in the blood.

\section{Experiments}

Since 1973 upwards 40 feeding experiments were carried out with dry or lactating Friesian cows aged from 3 to 8 years with a body weight of $415-670 \mathrm{~kg}$. The rations consisted of hay or pellets of artificially dried grass or turnips or freshly mown grass. The freshly mown grass consisted of monoculture ryegrass or cocksfoot. The animals were fed twice daily. For the lactating cows, if necessary, the roughage was supplemented with concentrates according to requirements. During the experiments all the cows were provided permanently with a catheter in the jugular vein for taking blood samples easily to determine $\mathrm{Hb}$ (hemoglobin) and the percentage of total $\mathrm{Hb}$ converted into $\mathrm{MHb}$. A number of animals was also provided with a rumen fistula. In this paper only results are mentioned of cows supplied with at least four meals of nitrate-rich roughage (nitrate-adapted animals). For the way in which the experiments were carried out, the sampling techniques and the chemical procedures we refer to Kemp et al. (1977). 


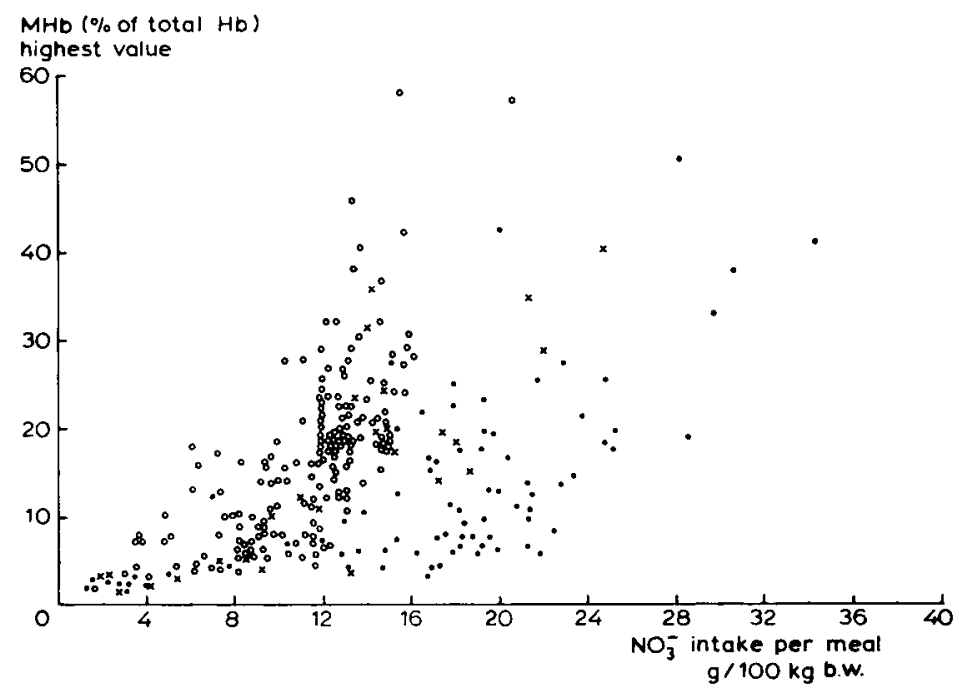

Fig. 1. Relation between nitrate intake with hay $(\bigcirc)$, turnips $(X)$ and freshly mown grass $(\bullet)$ in grammes of $\mathrm{NO}^{-3}$ per $100 \mathrm{~kg}$ body weight per meal and the formation of methemoglobin in blood of cows.

\section{Results and discussion}

Fig. 1 shows the relation between the dosage of nitrate per meal in grammes per $100 \mathrm{~kg}$ body weight and the highest $\mathrm{MHb}$ percentage (percentage of $\mathrm{MHb}$ of total $\mathrm{Hb}=\mathrm{Hb}+\mathrm{HbO}_{2}+\mathrm{MHb}$ ) in the blood found after one feeding. These highest $\mathrm{MHb}$ percentages were selected from a series of determinations which were found at intervals of 15 minutes after the intake of roughage and which have been used in Fig. 1 to 4. The experiments with cows on hay (Fig. 1) demonstrate a significant and positive relation between nitrate intake and $\mathrm{MHb}$ percentage in the blood. Probably there is no linear relationship which, for that matter, was neither to be expected and which agrees with the findings of Crawford (1960). When more than $15 \mathrm{~g}$ of $\mathrm{NO}_{3}^{-}$per $100 \mathrm{~kg}$ body weight are consumed per meal, dangerously high $\mathrm{MHb}$ contents of over $50 \%$ may occur. Above this level serious symptoms and death may occur within a few minutes. With an intake of $3 \mathrm{~g}$ or less with hay the $\mathrm{MHb}$ contents always remained normal, which is 2 to $3 \%$. However, the rather wide variation in $\mathrm{MHb}$ contents at the same nitrate intake is striking. Thus, with a nitrate intake in hay of about $15 \mathrm{~g}$ per $100 \mathrm{~kg}$ body weight the MHb percentages varied from 15 to $50 \%$.

The results of a much smaller number of experiments in which turnips were fed showed reasonably good correspondence with those with hay. However, in a number of cases appreciably lower $\mathrm{MHb}$ percentages were found on this roughage than were to be expected from the nitrate intake. Feeding of nitrate-rich grass resulted in relatively lower $\mathrm{MHb}$ percentages than feeding nitrate-rich hay or turnips. Dangerously high $\mathrm{MHb}$ percentages $(>50 \%$ ) after feeding nitrate-rich grass were 
observed in one case only, in which some $30 \mathrm{~g}$ of nitrate per $100 \mathrm{~kg}$ body weight were consumed, which is about twice the amount of nitrate in hay necessary to obtain the same high $\mathrm{MHb}$ values. Although no experiments were carried out in this respect, it is to be expected that rations of pre-wilted grass silage are comparable to those of hay.

In Fig. 2 the results of the experiments with hay, as reflected in Fig. 1, are separated into two groups, viz one group in which the nitrate-rich rations were consumed within 60 minutes and another group in which the rations were taken up in 60-120 minutes. This figure suggests that as a certain amount of nitrate-rich hay is taken up more slowly, less $\mathrm{MHb}$ is formed than with a more rapid intake. Hence with a slow intake of $10 \mathrm{~g}$ of nitrate an $\mathrm{MHb}$ percentage of about 10 is to be expected, whereas this will be almost 20 with a more rapid intake. The high intake speed of the nitrate can be caused by a high speed of dry matter intake or by a high nitrate content. At a low speed of intake of a nitrate dose up to $5 \mathrm{~g}$ per $100 \mathrm{~kg}$ body weight the MHb percentages in the blood remained normal.

In order to test the suggestion in Fig. 2 that the speed of intake is another factor in the formation of $\mathrm{MHb}$, an experiment was carried out with four lactating cows (see Fig. 3). Two groups of two experimental animals each were supplied with equal amounts of nitrate-rich roughage per $100 \mathrm{~kg}$ body weight: until 30 March as nitrate-rich hay, from 30 March to 11 April as grass or hay pellets and from 11 April until the end of the experiment as hay. Until 11 April one of the groups received the rations always in once and consumed it within 25 minutes, whereas for the other group the hay ration was divided into 8 equal parts of which one part was supplied every 15 minutes. Under the latter conditions the time of intake of

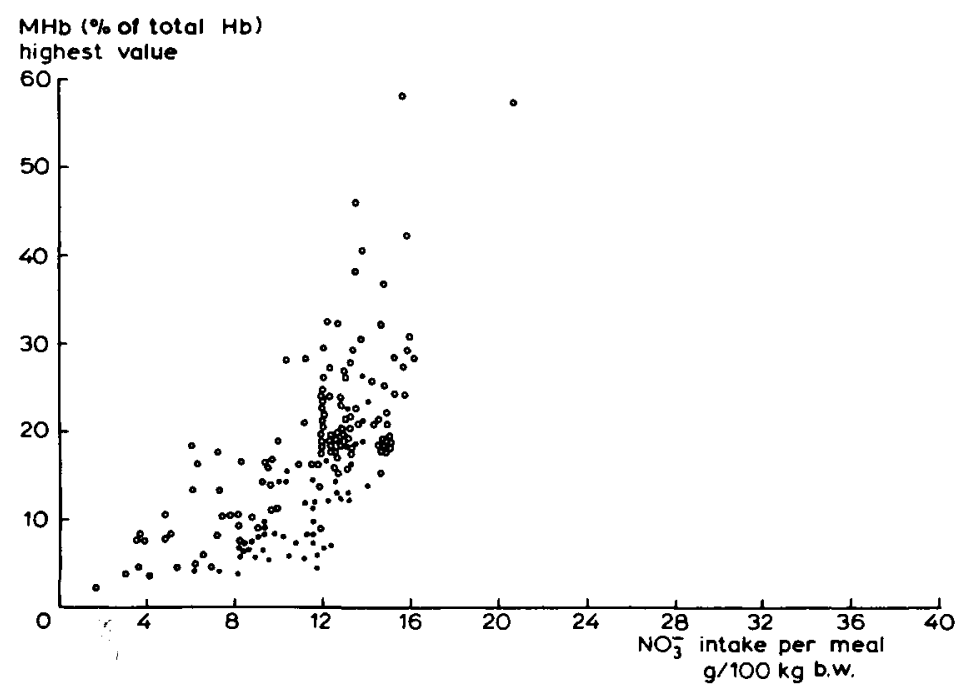

Fig. 2. Relation between nitrate intake with hay in grammes of $\mathrm{NO}^{-} 3$ per $100 \mathrm{~kg}$ body weight per mes and the formation of methemoglobin in blood of cows at different speeds of intake ( $O$ time of intake $<60$ minutes; $\bullet$ time of intake $60-120$ minutes). 


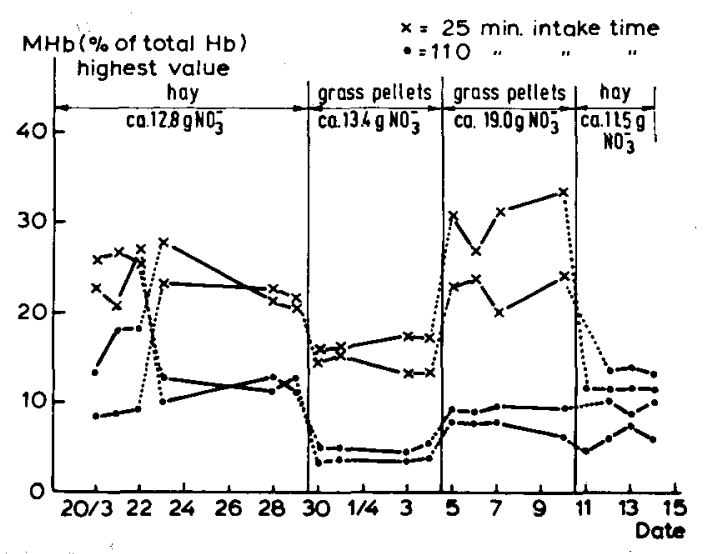

Fig. 3. Influence of speed of intake of nitrate-rich roughage on the formation of methemoglobin.

the total ration amounted to 110 minutes. During the first period the groups were exchanged on $23 \mathrm{March}$. In Fig. 3 the nitrate intakes per $100 \mathrm{~kg}$ body weight per meal have been mentioned above each experimental period. Since the animals had received nitrate-rich hay from $16 \mathrm{March}, \mathrm{MHb}$ determinations were carried out from 20 March. The effect of the different speeds at which the roughage was consumed is reflected in the figure. It is apparent that in all the periods a rapid intake of nitrate caused an appreciably higher $\mathrm{MHb}$ percentage than did a slower intake of an equal dose. Roughly it can be stated that at these dosages of nitrate taken in with hay the reduction in the speed of intake by extension of the intake time from 25 to 110 minutes resulted in halving the maximum $\mathrm{MHb}$ percentage, i.e. from approximately $22 \%$ to about $12 \%$. Despite the somewhat higher nitrate dose compared to the first period, from 30 March the MHb percentages in the group with a rapid intake as well as in the other group remained somewhat below the values determined for the hay rations under comparable conditions. For an explanation of this phenomenon more data are required. However, the effect of the intake speed of the nitrate is evident also in this case. From 5 April the rations of grass pellets were increased to a nitrate dose of about $19 \mathrm{~g}$ per $100 \mathrm{~kg}$ body weight. The rise in the nitrate intake is evident from the higher MHb percentages, while the differences in the speed of the nitrate intake caused appreciably differences in the $\mathrm{MHb}$ percentages. In all the periods of this experiment the suggestion, apparent from Fig. 2, that the speed of intake of the nitrate dose should affect the formation of $\mathrm{MHb}$ was confirmed.

From 11 April all the experimental animals were supplied with hay with a low nitrate content, i.e. $1 \%$ of $\mathrm{NO}_{3}^{-}$in the dry matter. This implied approximately $11.5 \mathrm{~g}$ of nitrate per $100 \mathrm{~kg}$ body weight in an intake time of 110 minutes for all the animals. The MHb percentages in the blood of the four experimental cows are now almost equal compared to the earlier periods in this experiment and also on a level that was to be expected on the basis of the nitrate intake and the speed of intake.

In view of the preceding it will be interesting to study to what extent the scatter 
in the relation between nitrate intake and the formation of $\mathrm{MHb}$, as shown in Fig. 1, can be explained by he differences in the speed of nitrate intake. Fig. 4 only includes those data from Fig. 1 in which the time of intake of the nitrate-rich hay, freshly mown grass and turnips was between 60-120 minutes. The average intake time of the various roughages was almost the same. For fresh grass the data of perennial ryegrass and cocks foot from pure culture were separately presented in this figure. The points in Fig. 4 show considerably les scatter than in Fig. 1 due to only using data of which the time of intake was between 60 and 120 minutes. In view of the preceding this was to be expected. However, at this speed of nitrate intake there still are important differences between the various roughages. The observed difference in Fig. 1 between hay and fresh grass in the formation of $\mathrm{MHb}$ can therefore not be explained solely by the differences in the speed of nitrate intake. For instance, an MHb percentage of 20 is first attained on hay, whereas on rations of turnips, cocksfoot or ryegrass more nitrate can be supplied before a level of $20 \%$ is attained. At a nitrate intake with ryegrass of a maximum of $9 \mathrm{~g}$ per $100 \mathrm{~kg}$ body weight the $\mathrm{MHb}$ percentages remain at a normal level: Most likely differences in the speed of intake have had an important effect in the experiments of Crawford (1960). Apart from the speed of nitrate intake, at least one other factor should be considered.

To explain the differences in MHb formation between the various nitrate-rich roughages we suggest a possible influence of the rate at which the nitrate in the roughages becomes available in the rumen as a substrate for the rumen flora. This was studied in an experiment in vitro. Various nitrate-rich feeds were submerged

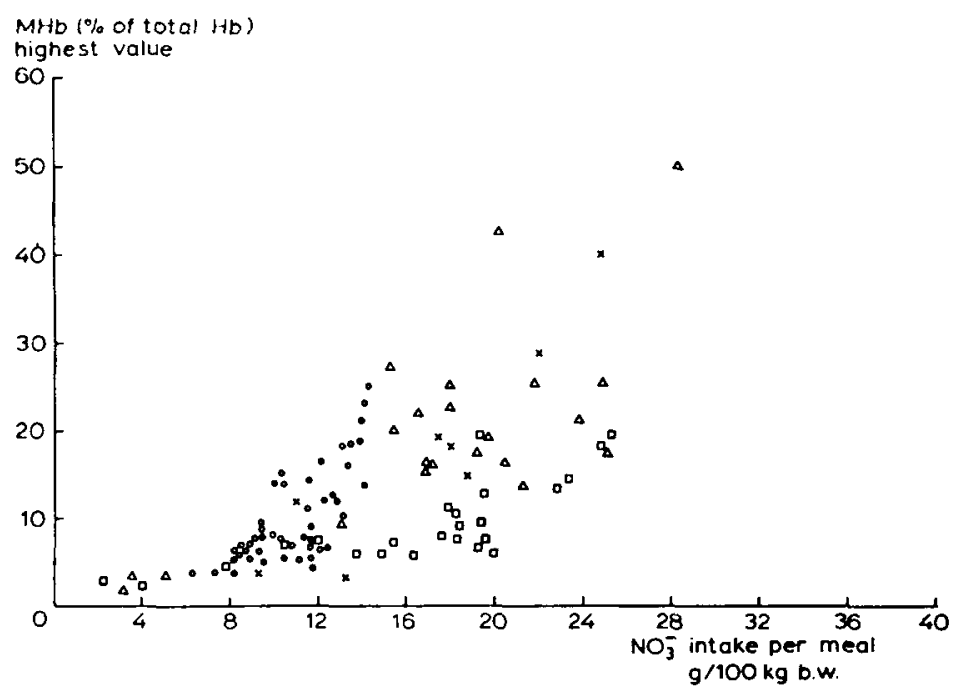

Fig. 4. Relation between nitrate intake with hay $(\bigcirc)$, turnips $(X)$, fresh cocksfoot $(\triangle)$ and fresh perennial ryegrass $(\square)$ in grammes of $\mathrm{NO}_{3}^{-}$per $100 \mathrm{~kg}$ body weight per meal and the formation of methemoglobin in cows with the same speed of intake (time of intake 60-120 minutes). 


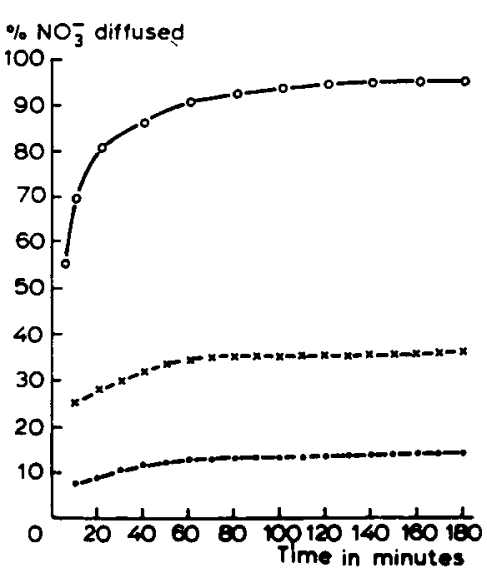

Fig. 5. Percentage of nitrate diffusing from various roughages after chopping to $1 \mathrm{~cm}$ and submerged in distilled water $(\bigcirc$ hay; $\times$ turnips (leaf + turnip); - fresh grass (ca. $90 \%$ perennial ryegrass)).

in demineralized water of $37{ }^{\circ} \mathrm{C}$, i.e. hay, turnips and fresh grass $(90 \%$ perennial ryegrass). All these roughages were chopped to $1 \mathrm{~cm}$ just before submergence. The water was kept at $37^{\circ} \mathrm{C}$ throughout the experiment. After submerging a water sample was taken every 10 minutes to analyse the nitrate content. The three forages tested contained a similar nitrate content of about $2.8 \% \mathrm{NO}_{3}^{-}$in the dry matter. The results of this trial are reflected in Fig. 5. The nitrate in the solution is presented as a percentage of the maximum concentration to be attained in the water volume (including the water from the roughage). The values per forage are averages of four replicates. The nitrate in the hay was for $80 \%$ in the solution after 20 minutes of submersion. The maximum of about $95 \%$ was attained after some 100 minutes. With turnips, however, only some $30 \%$ of the nitrate had diffused into the water after submergence during 20 minutes and the maximum which was only about $35 \%$ was attained after approximately 80 minutes. The nitrate from the freshly mown grass was the slowest to diffuse. After 20 minutes of submersion approximately $10 \%$ was found in the solution which then increased slowly to a maximum of $12 \%$ after 60 minutes. The difference in permeability of the cell membranes may explain this wide variation. In this way the cell membranes of hay, grass pellets and prewilted silage are completely permeable as a consequence of the preservation processes. Due to this the nitrate present in the cell can easily diffuse into the water. In the case of fresh products the concentration of nitrate entering the solution is dependent on the mechanical damage to the plant cells. By chopping a fresh forage to $1 \mathrm{~cm}$ only a small percentage of the plant cells is damaged, through which the nitrate can pass into the solution.

The results of the preceding experiment in vitro (Fig. 5) and the experiments in vivo (Fig. 4) suggest that the appreciably higher MHb percentages after nitrate-rich hay than after nitrate-rich grass are caused by a rapid release of nitrate from the hay in the rumen liquid, particularly since the speed of nitrate intake of the cows in Fig. 4 was kept at the same level (60-120 minutes). The differences in the effect between the nitrate-rich roughages on the MHb formation in Fig. 4, were therefore not caused by differences in the speed of intake, but probably by differences 
in the rate of release of the fodder nitrate into the rumen liquid. A higher concentration of nitrate in the rumen liquid will lead to a greater accumulation of nitrite and higher MHb percentages. In Fig. 4 as well as in Fig. 5 the turnips are intermediate.

In these observations it should be realized that the extent of the mechanical damage of the plant cells due to chewing and the effect of the rumen microbes is partly comparable to the pre-treatment as applied in the mentioned experiment in vitro. Other preliminary studies in vitro showed that the amount of nitrate in grass diffusing in water was increased by chopping the grass finely; however, values above $50 \%$ of nitrate were not found.

In addition, allowance has to be made for the possibility that the kind of roughage and its composition may affect the activity of the rumen flora and may lead to interference in the nitrate-nitrite-ammonia reduction pattern in the rumen and the formation of $\mathrm{MHb}$ in the blood.

Based on the experimental results as mentioned in this paper, we conclude that at least three factors are of importance in the formation of $\mathrm{MHb}$ in the blood of ruminants:

1) the amount of nitrate consumed. As more nitrate is consumed per meal a greater part of the $\mathrm{Hb}$ is converted into $\mathrm{MHb}$;

2) the speed of intake of the nitrate. The speed of nitrate intake is dependent on the speed of roughage intake and its nitrate content. As the speed of nitrate intake is higher more $\mathrm{Hb}$ is converted into $\mathrm{MHb}$ in the blood;

3 ) the rate at which the nitrate taken in with the roughage is released as a substrate for the rumen flora. As the nitrate in the rumen diffuses more rapidly higher $\mathrm{MHb}$ percentages will be attained in the blood.

In the Netherlands nitrate poisoning occurs regularly - though not frequently in cattle fed indoors on fresh grass or preserved roughage. No distinct evidence was found that nitrate poisoning also occurs during grazing of grass, although very high nitrate contents may occur. The explanation for this has been given in the preceding. The intake of grass by grazing animals is still slower than that of freshly mown grass indoors twice daily, as in our experiments, and still much slower than the intake of hay. In addition there is the much slower release of nitrate from the fresh grass compared to that of preserved roughage in the rumen liquid. It is therefore much less harmful if animals graze on grass with very high nitrate contents than if the grass is used to make hay and is fed as such.

\section{References}

Asbury, A. C. \& E. A. Rhode, 1964. Nitrite intoxication in cattle: The effects of lethal doses of nitrite on blood pressure. Am. J. vet. Res. 25: 1010-1013.

Crawford, R. F., 1960. Some effects of nitrate in forage in ruminant animals. Ph. D. thesis, Cornell University, Ithaca, N.Y., p. 1-156.

Dollahite, J. W. \& E. C. Holt, 1970. Nitrate poisoning. S.Afr. Med. Tijdskr. (14 Feb.): 171-174.

Gamgee, A., 1868. Researches on the blood. On the action of nitrites on blood. Phil. Trans. Roy. Soc. Lond.: 589-625. 
Kemp, A., J. H. Geurink, R. T. Haalstra \& A. Malestein, 1976. Nitrate poisoning in cattle. 1. Discoloration of the vaginal mucous membrane as aid in the prevention of nitrate poisoning in cattle. Stikstof 19:40.

Kemp, A., J. H. Geurink, R. T. Haalstra \& A. Malestein, 1977. Nitrate poisoning in cattle. 2. Changes in nitrite in rumen fluid and methemoglobin formation in blood after high nitrate intake. Neth. J. agric. Sci. 25: 51-62.

Kemp, A., J. H. Geurink, A. Malestein \& A. Th. van 't Klooster, 1978a. Grassland production and nitrate poisoning in cattle. Rep. Proc. 7 th gen. Meet. Eur. Grassld Fedn (Gent).

Kemp, A., J. H. Geurink, A. Malestein \& A. Th. van 't Klooster, 1978b. Stickstoffdüngung des Grünlandes und Nitratvergiftung beim Rind. Tierzüchter 30: 297-300.

Malestein, A., J. H. Geurink, G. Schuyt \& A. J. H. Schotman, 1979. Nitrate poisoning in cattle. 4. The effect of nitrite dosing during parturition on the oxygen capacity of maternal blood and the oxygen supply of the unborn calf. (In preparation).

Vertregt, N., 1977. The formation of methemoglobin by the action of nitrite on bovine blood. Neth. J. agric. Sci. 25: 243-254. 